\title{
Carepath for overcoming psychosis early (COPE): first 5 years of clinical operation and prospective research in the Cavan-Monaghan early intervention service
}

\author{
S. Fayyaz ${ }^{1}$, N. Nkire ${ }^{1,2}$, B. Nwosu ${ }^{1}$, N. Amjad ${ }^{1}$, A. Kinsella ${ }^{2}$, M. Gill ${ }^{1,3}$, C. McDonough ${ }^{1,4}$, \\ V. Russell ${ }^{1,3}$ (D) and J. L. Waddington ${ }^{2 * *}$ (D) \\ ${ }^{1}$ Cavan-Monaghan Mental Health Service, Drumalee Primary Care Centre, Cavan, Ireland \\ 2 School of Pharmacy and Biomolecular Sciences, Royal College of Surgeons in Ireland, Dublin, Ireland \\ ${ }^{3}$ Department of Psychiatry, Royal College of Surgeons in Ireland, Beaumont Hospital, Dublin, Ireland \\ ${ }^{4}$ Louth Mental Health Service, St. Brigid's Hospital, Ardee, Ireland
}

Objectives: As Ireland confronts the many challenges of broadening the introduction of early intervention services (EIS) for first episode psychosis (FEP) as national policy, this article describes Carepath for Overcoming Psychosis Early (COPE), the EIS of Cavan-Monaghan Mental Health Service, and presents prospective research findings during its first 5 years of operation.

Methods: COPE was launched as a rural EIS with an embedded research protocol in early 2012, following an education programme for general practitioners (GPs). Here, operational activities are documented and research findings presented through to late 2016.

Results: During this period, 115 instances of FEP were incepted into COPE, $70.4 \%$ via their GP and 29.6\% via the Emergency Department. The annual rate of inception was $24.8 / 100,000$ of population aged $>15$ years and was 2.1-fold more common among men than women. Mean duration of untreated psychosis was 5.7 months and median time from first psychotic presentation to initiation of antipsychotic treatment was zero days. Assessments of psychopathology, neuropsychology, neurology, premorbid functioning, quality of life, insight, and functionality compared across 10 DSM-IV psychotic diagnoses made at six months following presentation indicated minimal differences between them, other than more prominent negative symptoms in schizophrenia and more prominent mania in bipolar disorder.

Conclusions: COPE illustrates the actuality of introducing and the challenges of operating a rural EIS for FEP. Prospective follow-up studies of the 5-year COPE cohort should inform on the effectiveness of this EIS model in relation to long-term outcome in psychotic illness across what appear to be arbitrary diagnostic boundaries at FEP.

Received 18 December 2020; Revised 11 June 2021; Accepted 24 June 2021

Key words: First episode psychosis, early intervention, service models, diagnostic boundaries, duration of untreated psychosis.

\section{Introduction}

Provision of early intervention services (EIS) for psychotic illness now holds a central position in mental health care. This primacy derives from meta-analytic evidence across 13 indices of outcome in 10 randomised clinical trials (Correll et al. 2018), supplemented by evidence for reduced risk for suicide (Chan et al. 2018) and judicial outcome (Pollard et al. 2020). In the real-world setting of the Irish public health services, longer durations of untreated psychosis and of untreated illness are associated with increasing impairment (Clarke et al. 2016; Nkire et al. 2021a) and we have

*Address for correspondence: Professor J. Waddington, School of Pharmacy and Biomolecular Sciences, Royal College of Surgeons in Ireland, St. Stephen's Green, Dublin, 2, Ireland

(Email: jwadding@rcsi.ie) recently reported health economic advantage for EIS using the net benefit approach (Behan et al. 2020).

The journey to EIS in Ireland has been authoritatively reviewed by Power (2019). Establishment of DETECT in 2007 (Omer et al. 2010) was a pioneering event that long preceded the Health Service Executive National Clinical Programme for Early Intervention in Psychosis and subsequently facilitated the establishment of a second EIS, the Cavan-Monaghan Mental Health Service (CMMHS) Carepath for Overcoming Psychosis Early (COPE) in 2012 (Nkire et al. 2015). Since then: DETECT has reported prospective findings over its first 7 years of operation (Lyne et al. 2015); the North Lee Mental Health Service has reported a retrospective, descriptive study of their EIS over a 5-year period (Lalevic et al. 2019); the South Lee Mental Health Service has reported a retrospective case 
review of a pilot EIS over a 14-month period (Murray \& O'Connor, 2019). This article first outlines the realworld actualities and vicissitudes of the development and operation of COPE.

\section{Carepath for overcoming psychosis early}

\section{Development and operation}

As described previously in detail (Waddington \& Russell, 2019), in 1995 philanthropic funding allowed the initiation of two parallel studies of first episode psychosis (FEP): one involving the St. John of God Hospitaller Ministries and Cluain Mhuire Community Mental Health Services (hereafter SJoG); the other involving CMMHS and the Royal College of Surgeons in Ireland [hereafter the Cavan-Monaghan First Episode Psychosis Study (CAMFEPS)]. Between 1995 and 1999, these two studies operated in parallel, using overlapping staff training and assessment methods. Thereafter, the SJoG study evolved into DETECT (Omer et al. 2010), while CAMFEPS continued through to 2010, after which it evolved into COPE (Nkire et al. 2015).

Fundamental to CAMFEPS was a model based on a registrar/clinical research fellow having both sessional service commitments and a research role via embedding within CMMHS. Thus, he/she was integral to CMMHS, in which primary care liaison and use of home-based treatment as an alternative to hospital admission are central to the delivery of mental health services (McCauley et al. 2003; Russell et al. 2003, 2019; Nwachukwu et al. 2014). In 2009, during which CAMFEPS was completing its 15-year tenure, CMMHS took the decision to establish COPE as Ireland's first rural-based EIS. With advice from DETECT, this led to a prototype EIS model that combined the DETECT experience with the particular setting and requirements of CMMHS, together with their shared commitment to embedded research studies, followed by refinement of an integrated, multidisciplinary EIS model with attendant challenges vis-à-vis availability of resources within an already stretched health service. As part of the development process each General Practitioner (GP) in counties Cavan and Monaghan was invited to participate in a study to evaluate their baseline knowledge of and attitudes to psychotic illness, followed by delivery of an education programme to increase awareness and encourage rapid referral of psychosis (Nkire et al. 2015). The last of 432 subjects was incepted into CAMFEPS in April 2010 (Nkire et al. 2021b) under the care of CMMHS. Progressively, through to December 2011, 33 individuals with newly presenting FEP were incepted into the prototype COPE model and, following refinements, in January 2012 the COPE model was launched by CMMHS as its EIS for FEP.

The COPE EIS model (Nkire et al. 2015) for persons presenting with FEP at age 16 and above in counties Cavan or Monaghan [total population 133,666 (2011 census)] involved tailored, evidence-based interventions provided through the Community Mental Health Team (CMHT), Child and Adolescent Mental Health Service (CAMHS), and Mental Health Service for the Elderly (MHSE). From bases in Cavan and Monaghan, these included: pharmacological and psychological treatment, including cognitive behavioural therapy for psychosis; social skills training and occupational therapy; behavioural family therapy; metabolic profiling; clinical follow-ups to evaluate treatment response and metabolic profile at 3,6, and 12 months; where necessary, the community rehabilitation service was available. The COPE team included, from within existing resources, a consultant lead for its clinical arm, an academic lead for its research arm, a COPE registrar, a senior clinical psychologist, an occupational therapist, a social worker, and a COPE administrator. This team met regularly to oversee COPE activities. GPs in the catchment areas were the primary source of referrals to CMMHS, which were facilitated by regular on-site liaison visits to their practices as part of the established primary care liaison service (Russell et al. 2003, 2019).

\section{Postscript}

COPE operated as described above between 2012 and 2016, including sequential appointments of a COPE registrar integral to CMMHS. These embedded appointments, each having tenure for 2 years, were established during CAMFEPS (Russell et al. 2019) and continued thereafter to include involvement in the development of COPE and then a fundamental role in its day-to-day activities under the supervision of the clinical and academic leads. In 2016, diminishing resources no longer allowed for such 2-year appointments, which were reduced to a 1-year and subsequently a 6-month tenure in accordance with conventional Non-Consultant Hospital Doctor rotations. The length of induction for each appointee, which required extensive training with his/her predecessor at COPE and colleagues at DETECT before and following their appointment, became problematic given such brevity of tenure and, in efforts to sustain COPE, the number of assessment instruments was substantially reduced. Critically, such attrition in resources extended to the non-replacement and diversion of allied health professionals previously allocated to COPE; these included diminution in psychology services and lack of cover for maternity leave in occupational therapy 
and social work. Recognising the National Clinical Programme for Early Intervention in Psychosis vis-àvis the breadth and depth of demands on resources in CMMHS, priorities were directed more broadly to CMHT. In the face of such vicissitudes and associated restructuring, and despite the best endeavours of the COPE team, the clinical lead ultimately felt that this service could not be sustained to the required standard. Thus, COPE was suspended by CMMHS in May 2019 pending the availability of appropriate resources.

Nevertheless, data accumulated during the operation of COPE constitute a rich resource for prospective studies of the impact of EIS on an FEP cohort from initial presentation to long-term outcome. While the assessments to be detailed below were integral to clinical care under the COPE service, the Research Ethics Committee of the Health Service Executive Dublin North East Area gave approval for patient data to be used also for research to advance understanding of psychotic illness and health care provision. This included subjects giving written informed consent to such use of their data after this had been fully explained; informed consent was also sought from a parent or guardian for those aged 16 or 17 . Here, initial findings on inceptions into COPE during 2012-2016 are described.

\section{Aims}

To: (i) document the development and operation of this rural EIS; and (ii) compare clinical characteristics across diagnoses to address enduring controversies regarding the extent to which boundaries between psychotic diagnoses are arbitrary and porous in the face of continuously distributed dimensions of psychopathology (Guloksuz \& van Os, 2018; Nkire et al. 2021b).

\section{Methods \\ Data collection}

The following demographics were recorded for inceptions into COPE: age, sex, marital status, employment status, referral source to CMMHS (via GP or Emergency Department), referral source from CMMHS to COPE (via CMHT, CAMHS or MHSE), and COPE intervention (required or not required). Each COPE registrar gained competency in use of the assessment instruments via training delivered by both their predecessors and the generosity of colleagues in DETECT. Training of each COPE registrar took place before and during the early course of replacing their predecessor in assessment of FEP cases. Following referral for initial clinical evaluation and intervention, subjects incepted into COPE entered formal assessments as soon as was practicable using first the
Structured Clinical Interview for DSM-IV Axis I Disorders (First et al. 2002); at 6 months thereafter, all clinical information, to include case notes and discussions with treating teams, were reviewed to confirm or update the initial DSM-IV diagnosis as more stable and representative (Baldwin et al. 2005; Nkire et al. 2021b). Then, the instruments indicated below were applied.

Psychopathology was assessed using: (i) the Positive and Negative Syndrome Scale (PANSS; Kay et al. 1987) for continuity with CAMFEPS, as total score (PANSS-t) and subscale scores for positive (PANSS-p), negative (PANSS-n) and general (PANSS-g) symptoms; and (ii) for greater incisiveness the Scale for the Assessment of Positive Symptoms (SAPS; Andreasen, 1984), Scale for Assessment of Negative Symptoms (SANS; Andreasen, 1983), Young Mania Rating Scale (YMRS; Young et al. 1978), and Calgary Depression Scale for Schizophrenia (CDSS; Addington et al. 1990).

Cognition was first assessed using the Mini-Mental State Examination (MMSE; Folstein et al. 1975) for general cognition and the Executive Interview (EXIT; Royall et al. 1992) for executive/frontal lobe function (Baldwin et al. 2005; Nkire et al. 2021b).

Extrapyramidal movement disorder was assessed using the Simpson-Angus Scale (SAS; Simpson \& Angus, 1970). Involuntary movements were assessed using the Abnormal Involuntary Movement Scale (AIMS; Guy, 1976).

Premorbid intellectual functioning was assessed using the National Adult Reading Test (NART; Nelson, 1982). Premorbid adjustment was assessed using the Premorbid Adjustment Scale (PAS; Cannon-Spoor et al. 1982).

Insight was assessed using the Scale to Assess Unawareness of Mental Disorder (SUMD; Amador et al. 1993) and the Birchwood Insight Scale (BIS; Birchwood et al. 1994).

Quality of life was assessed using the Quality of Life Scale (QLS; Heinrichs et al. 1984). Functioning was evaluated using the MIRECC version of the Global Assessment of Functioning Scale (MGAF; Niv et al. 2007), with subscale scores for occupational (MGAF1), social (MGAF2), and symptomatic (MGAF3) functioning.

Duration of untreated psychosis (DUP) and duration of untreated illness (DUI) were assessed using the scale of Beiser and colleagues (Beiser et al. 1993): DUP was defined as the period between first noticeable psychotic symptoms and receipt of antipsychotic treatment; DUI was defined as the period between first noticeable behavioural abnormality and receipt of antipsychotic treatment (Beiser et al. 1993; Nkire et al. 2021a). Information used in completing this scale was derived from interview with the patient regarding 
illness and psychosis onset, review of all medical records, interview with initial clinicians where possible, and interview with family and friends where available and able to give information regarding illness and psychosis onset.

\section{Statistical analysis}

This followed previously described procedures (Nkire et al. 2021a, 2021b). Rate of inception into COPE is expressed as the annual number of cases per 100,000 of population aged $\geq 15$ years (2011 census), with $95 \%$ confidence intervals (CI) for rates and rate ratios (RR). These analyses were performed using Stata Release 14. Demographic and assessment data are expressed as means with standard deviations (s.D.) and, for age, DUP and DUI, also as medians with interquartile ranges (IQR). For diagnoses having five or more cases, data for each demographic and clinical variable were analysed using analysis of variance (ANOVA) followed by Dunnett's test that compared each diagnosis to schizophrenia as reference. Because of their substantially right-skewed distributions (see Results), DUP and DUI were analysed following the transformations $\log 10[1+\mathrm{DUP}]$ (Norman \& Malla, 2001; Nkire et al. 2021a) and $\log 10[1+\mathrm{DUI}]$, respectively, hereafter referred to as $\log$ DUP and $\log$ DUI. Significance was indicated by $p<0.05$. For diagnoses having less than five cases, formal statistical analysis was precluded and data are presented descriptively.

\section{Results}

\section{Operation of COPE}

Over the 4.5-year period between January 2012 and June 2016, 115 individuals with FEP [78 male (67.8\%), 37 female (32.2\%)] were incepted into COPE. The majority of cases were referred initially to CMMHS via their GP $[81(70.4 \%)]$ and a minority via the Emergency Department [34 (29.6\%)], with females [16 of 37 $(43.2 \%)]$ more likely to be referred by the Emergency Department than males [18 of $78(23.1 \%) ; p<0.05]$. From CMMHS, the majority of inceptions were referred to COPE via CMHT [111 (96.5\%)] and minorities via CAMHS [2 (1.7\%)] and MHSE [2 (1.7\%)]. Patterns of inception did not differ between the sexes. Of the 115 inceptions, 104 [71 of 78 males (91.0\%), 33 of 37 females $(89.2 \%)$ ] were subsequently deemed to require COPE intervention and 11 [7 males $(9.0 \%)$, 4 females (10.8\%)] were subsequently deemed not to require COPE intervention; the reasons for incepted cases not requiring COPE intervention were brief psychotic disorder, which by definition involves a transient FEP that rapidly resolves, and instances of psychotic disorder due to a general medical condition where that medical condition could be readily addressed.

A small number of FEP cases presenting to CMMHS and referred to COPE were not incepted for reasons that included: history of previous presentation(s) with a psychotic episode; occasional decisions to optimise care by retaining individual FEP cases within CAMHS and particularly MHSE; absence of clinical evidence of psychosis, a small number of whom were considered to show signs of the prodrome of psychotic illness (Clarke et al. 2016) [sometimes referred to as attenuated psychosis syndrome (Salazar de Pablo et al. 2020) or clinical high risk for psychosis (Fusar-Poli, 2017)]. COPE was not conceived or structured to intervene in such instances, which were managed within CMMHS. Operational reasons for non-inception included: deceased or relocated from the catchment area between FEP and inception; CMMHS policy that two successive non-attendances at appointments results in discharge from its services.

Among the 115 cases incepted into COPE, following first psychotic presentation to a GP or to the Emergency Department median time to referral to CMMHS was 0 days [mean 0.4 (s.D. 2.6), range 0-27 days]. Following referral to CMMHS for initial evaluation and care, median time to referral to COPE was 7 days [mean 11.4 (s.D. 13.3), range 0-72 days]. Following inception into COPE for initiation of the EIS programme, median time to commencing formal assessments was 12 days [mean 16.6 days (S.D. 14.5), range 0-68 days]. As elaborated further below, following first psychotic presentation median time to initiation of antipsychotic treatment was 0 days [mean 0.4 (s.D. 2.9), range 0-27 days].

The majority of inceptions into COPE had never married [66 (57.4\%)] or were married/in a long-term relationship [36 (31.3\%)], widowed [3 $(2.6 \%)]$, divorced [5 $(4.3 \%)$ ] or separated [5 $(4.3 \%)]$. The majority of referrals were unemployed [69 $(60.0 \%)]$; for one $(0.9 \%)$ employment status could not be established. Social demography did not differ between the sexes.

\section{Demographics}

The 115 inceptions into COPE received DSM-IV diagnoses at 6 months as follows: schizophrenia (SZ), $n=39$; schizophreniform disorder (SF), $n=3$; brief psychotic disorder $(\mathrm{BrP}), n=7$; schizoaffective disorder (SA), $n=2$; bipolar I disorder (BD), $n=13$; major depressive disorder with psychotic features (MDDP), $n=26$; delusional disorder (DD), $n=3$; substance-induced psychotic disorder (SIP), $n=15$; psychotic disorder due to a general medical condition (PGMC), $n=5$ (one arteriovenous malformation, one hyperthyroidism, one hypothyroidism, two temporal lobe epilepsy); 
psychotic disorder not otherwise specified (PNOS), $n=2$. No cases of substance-induced mood disorder with manic features, or mood disorder due to a general medical condition, with manic features, were encountered.

Table 1 shows mean and median ages at inception into COPE by sex across all diagnoses and for each diagnostic category at 6 months. Median age was lower than the mean for most diagnoses, due to the majority referred at younger ages, except for BrP or PNOS. There were no differences in age at inception between the sexes.

Table 2 shows the rate of inception into COPE by sex across all diagnoses and for each diagnostic category at 6 months. Annual rate was $24.8 / 100,000$ of population aged $\geq 15$ years. Rate for inception into COPE was higher among males than females for the following diagnostic categories: 2.1-fold higher $(p<0.001)$ across all psychoses; 3.3-fold higher $(p<0.001)$ for SZ; 13.9-fold higher $(p<0.001)$ for SIP.

\section{Clinical assessments}

Assessments of psychopathology are shown in Table 3. PANSS-t, PANSS-p, and PANSS-g scores did not differ from SZ for any other diagnostic category. PANSS-n score was lower $(p<0.02)$ in BD than in SZ, but did not differ from SZ for any other diagnostic category. SAPS score did not differ from SZ for any diagnostic category. SANS score was lower in BD $(p<0.001)$, MDDP $(p<0.05)$, SIP $(p<0.05)$, and PGMC $(p<0.01)$ than in SZ, but did not differ from SZ for any other diagnostic category. YMRS score was higher $(p<0.02)$ in BD than in SZ, but did not differ from SZ for any other diagnostic category. CDSS score did not differ from SZ for any diagnostic category. There were no differences between the sexes and all scores were unrelated to age.

Assessments of neuropsychology are shown in Table 4. Neither MMSE nor EXIT scores differed from SZ for any diagnostic category. There were no differences between the sexes. MMSE score decreased with age $(p<0.02)$, while EXIT score was unrelated to age. Across all diagnoses at 6 months, mean SAS score [0.4 (s.D. 0.9), $n=102$ ] and AIMS score [0.1 (s.D. 0.5), $n=103$ ] were so low as to preclude statistical analysis (data not shown).

Assessments of insight are shown in Table 4. Neither Birchwood Insight Scale nor SUMD scores differed from SZ for any diagnostic category. While there was no difference in BIS score between the sexes, SUMD scores were lower in females than in males $(p<0.05)$; both scores were unrelated to age.
Table 1. Number of cases incepted into COPE and age at first presentation by diagnostic category at 6 months

\begin{tabular}{|c|c|c|c|}
\hline Diagnosis & Total & Male & Female \\
\hline \multirow[t]{4}{*}{ All psychoses } & 115 & 78 & 37 \\
\hline & $29.8(12.9)$ & $28.3(11.1)$ & $33.0(15.7)$ \\
\hline & $26\{12\}$ & $24\{11\}$ & $29\{17\}$ \\
\hline & [16-91] & [16-67] & [16-91] \\
\hline \multirow[t]{4}{*}{$\mathrm{SZ}$} & 39 & 30 & 9 \\
\hline & $28.2(13.4)$ & $27.8(12.7)$ & $29.7(16.4)$ \\
\hline & $23\{13\}$ & $23\{11\}$ & $25\{15\}$ \\
\hline & [16-70] & [18-67] & [16-70] \\
\hline \multirow[t]{4}{*}{ SF } & 3 & 3 & 0 \\
\hline & $27.0(-)$ & $27.0(-)$ & - \\
\hline & $26\{-\}$ & $26\{-\}$ & - \\
\hline & [20-35] & [20-35] & - \\
\hline \multirow[t]{4}{*}{$\mathrm{BrP}$} & 7 & 4 & 3 \\
\hline & $32.3(10.0)$ & $28.3(7.2)$ & $37.7(12.1)$ \\
\hline & $31\{18\}$ & $28\{14\}$ & $42\{-\}$ \\
\hline & [21-47] & [21-37] & [24-47] \\
\hline \multirow[t]{4}{*}{ SA } & 2 & 0 & 2 \\
\hline & $39.0(-)$ & - & $39.0(-)$ \\
\hline & $39\{-\}$ & - & $39\{-\}$ \\
\hline & [25-53] & - & [25-53] \\
\hline \multirow[t]{4}{*}{$\mathrm{BD}$} & 13 & 7 & 6 \\
\hline & $35.5(20.8)$ & 31.9 (12.9) & $39.8(28.2)$ \\
\hline & $28\{28\}$ & $28\{21\}$ & $28\{44\}$ \\
\hline & [19-91] & [19-55] & [19-91] \\
\hline \multirow[t]{4}{*}{ MDDP } & 26 & 15 & 11 \\
\hline & 30.7 (11.4) & 30.1 (12.8) & $31.6(9.7)$ \\
\hline & $26\{10\}$ & $26\{13\}$ & $30\{7\}$ \\
\hline & [19-63] & [19-63] & [20-52] \\
\hline \multirow[t]{4}{*}{$\mathrm{DD}$} & 3 & 3 & 0 \\
\hline & $27.7(-)$ & $27.7(-)$ & - \\
\hline & $30\{-\}$ & $30\{-\}$ & - \\
\hline & [20-33] & [20-33] & - \\
\hline \multirow[t]{4}{*}{ SIP } & 15 & 14 & 1 \\
\hline & $26.1(7.9)$ & $26.6(7.9)$ & $19(-)$ \\
\hline & $23\{8\}$ & $25\{18\}$ & $19\{-\}$ \\
\hline & [19-45] & [20-45] & {$[-]$} \\
\hline \multirow[t]{4}{*}{ PGMC } & 5 & 1 & 4 \\
\hline & $34.8(5.8)$ & $37.0(-)$ & $34.3(6.6)$ \\
\hline & $37\{11\}$ & $37\{-\}$ & $34\{13\}$ \\
\hline & [40-76] & {$[-]$} & [27-42] \\
\hline \multirow[t]{4}{*}{ PNOS } & 2 & 1 & 1 \\
\hline & $17.5(-)$ & $16(-)$ & $19(-)$ \\
\hline & $17.5\{-\}$ & $16\{-\}$ & $19\{-\}$ \\
\hline & [16-19] & {$[-]$} & {$[-]$} \\
\hline
\end{tabular}

SZ, schizophrenia; SF, schizophreniform disorder; BrP, brief psychotic disorder; SA, schizoaffective disorder; BD, bipolar I disorder; MDDP, major depressive disorder with psychotic features; DD, delusional disorder; SIP, substance-induced psychotic disorder; PGMC, psychotic disorder due to a general medical condition; PNOS, psychotic disorder not otherwise specified.

Data are number of cases, mean age (s.D.), median \{interquartile range\}, [range]. 
Table 2. Annual rate of inception into COPE by diagnostic category at 6 months

\begin{tabular}{|c|c|c|c|c|}
\hline Diagnosis & Total & Male & Female & $\mathrm{RR}$ \\
\hline \multirow[t]{2}{*}{ All psychoses } & $\begin{array}{c}24.8 \\
(20.5-29.8)\end{array}$ & $\begin{array}{c}33.6 \\
(26.5-41.9)\end{array}$ & $\begin{array}{c}16.0 \\
(11.3-22.1)\end{array}$ & $\begin{array}{c}2.09^{* * *} \\
(1.42-3.10)\end{array}$ \\
\hline & 115 & 78 & 37 & \\
\hline \multirow[t]{2}{*}{ SZ } & $\begin{array}{c}8.4 \\
(6.0-11.5)\end{array}$ & $\begin{array}{c}12.9 \\
(8.7-18.4)\end{array}$ & $\begin{array}{c}3.9 \\
(1.8-7.4)\end{array}$ & $\begin{array}{c}3.31^{* * *} \\
(1.57-6.97)\end{array}$ \\
\hline & 39 & 30 & 9 & \\
\hline SF & $\begin{array}{c}0.6 \\
(-) \\
3\end{array}$ & $\begin{array}{c}1.3 \\
(-) \\
3\end{array}$ & $\begin{array}{c}0.0 \\
(-) \\
0\end{array}$ & - \\
\hline \multirow[t]{2}{*}{$\mathrm{BrP}$} & $\begin{array}{c}1.5 \\
(0.6-3.1)\end{array}$ & $\begin{array}{c}1.7 \\
(0.5-4.4)\end{array}$ & $\begin{array}{c}1.3 \\
(0.3-3.8)\end{array}$ & $\begin{array}{c}1.32 \\
(0.30-5.92)\end{array}$ \\
\hline & 7 & 4 & 3 & \\
\hline SA & $\begin{array}{c}0.4 \\
(-) \\
2\end{array}$ & $\begin{array}{c}0.0 \\
(-) \\
0\end{array}$ & $\begin{array}{c}0.9 \\
(-) \\
2\end{array}$ & - \\
\hline $\mathrm{BD}$ & $\begin{array}{c}2.8 \\
(1.5-4.8) \\
13\end{array}$ & $\begin{array}{c}3.0 \\
(1.2-6.2) \\
7\end{array}$ & $\begin{array}{c}2.6 \\
(1.0-5.7) \\
6\end{array}$ & $\begin{array}{c}1.16 \\
(0.39-3.45)\end{array}$ \\
\hline \multirow[t]{2}{*}{ MDDP } & $\begin{array}{c}5.6 \\
(3.7-8.2)\end{array}$ & $\begin{array}{c}6.5 \\
(3.6-10.6)\end{array}$ & $\begin{array}{c}4.8 \\
(2.4-8.5)\end{array}$ & $\begin{array}{c}1.35 \\
(0.62-2.95)\end{array}$ \\
\hline & 26 & 15 & 11 & \\
\hline $\mathrm{DD}$ & $\begin{array}{c}0.6 \\
(-) \\
3\end{array}$ & $\begin{array}{c}1.3 \\
(-) \\
3\end{array}$ & $\begin{array}{c}0.0 \\
(-) \\
0\end{array}$ & - \\
\hline \multirow[t]{2}{*}{ SIP } & $\begin{array}{c}3.2 \\
(1.8-5.3)\end{array}$ & $\begin{array}{c}6.0 \\
(3.3-10.1)\end{array}$ & $\begin{array}{c}0.4 \\
(0.0-2.4)\end{array}$ & $\begin{array}{c}13.90^{* * *} \\
(1.83-105.73)\end{array}$ \\
\hline & 15 & 14 & 1 & \\
\hline \multirow[t]{2}{*}{ PGMC } & $\begin{array}{c}1.1 \\
(0.4-2.5)\end{array}$ & $\begin{array}{c}0.4 \\
(0.0-2.4)\end{array}$ & $\begin{array}{c}1.7 \\
(0.5-4.4)\end{array}$ & $\begin{array}{c}0.25 \\
(0.03-2.22)\end{array}$ \\
\hline & 5 & 1 & 4 & \\
\hline PNOS & $\begin{array}{c}0.4 \\
(-) \\
2\end{array}$ & $\begin{array}{c}0.4 \\
(-) \\
1\end{array}$ & $\begin{array}{c}0.4 \\
(-) \\
1\end{array}$ & $\begin{array}{c}1.00 \\
(-)\end{array}$ \\
\hline $\begin{array}{l}\text { SZ, schizophrenia; } \\
\text { disorder; MDDP, } \\
\text { psychotic disorder } \\
\text { specified. } \\
\text { Data are annual ra } \\
\text { RR, relative risk in } \\
* * * p<0.001 \text { risk }\end{array}$ & $\begin{array}{l}\text { ohreniform dis } \\
\text { ressive disorde } \\
\text { sychotic disorc } \\
\text { of population } \\
\text { males }(95 \% \text { co } \\
\text { ales than in fel }\end{array}$ & $\begin{array}{l}\text {, brief psychotic } \\
\text { sychotic feature } \\
\text { general medica } \\
\\
(95 \% \text { confidence } \\
\text { nterval). }\end{array}$ & $\begin{array}{l}\text {; SA, schizoaffec } \\
\text { elusional disord } \\
\text { n; PNOS, psych } \\
\text { with number of }\end{array}$ & $\begin{array}{l}\text { der; BD, bipolar I } \\
\text { dbstance-induced } \\
\text { ler not otherwise }\end{array}$ \\
\hline
\end{tabular}

Assessments of quality of life and functioning are shown in Table 4. Neither QLS nor MGAF1/2/3 scores differed from SZ for any diagnostic category. There were no differences in QLS or MGAF1/2/3 scores between the sexes and both scores were unrelated to age.

Assessments of premorbid features and DUP/DUI are shown in Table 5. Neither NART nor PAS scores differed from SZ for any diagnostic category. There were no differences in scores between the sexes and both scores were unrelated to age. Median DUP and DUI were shorter than their respective means by many months across all diagnoses and for SZ, BrP, MDDP, SIP, and PGMC, due to the majority of cases having relatively short durations and a minority having considerably longer durations that indicated substantially right-skewed distributions. DUI was substantially longer than DUP in terms of both mean and median across all diagnoses and for $\mathrm{SZ}, \mathrm{BrP}$, MDDP, SIP, and PGMC. In contrast, for BD both durations were brief and considerably shorter than for SZ (DUP, $p=0.05$; DUI, $p=0.02$ ). There were no differences between the sexes and both measures were unrelated to age. 
Table 3. PANSS, SAPS, SANS, YMRS, and CDSS psychopathology scores by diagnostic category at 6 months

\begin{tabular}{|c|c|c|c|c|c|c|c|c|}
\hline Diagnosis & PANSS-t & PANSS-p & PANSS-n & PANSS-g & SAPS & SANS & YMRS & CDSS \\
\hline \multirow[t]{2}{*}{ All psychoses } & $61.2(19.6)$ & $18.3(7.7)$ & $13.7(6.8)$ & $29.2(9.3)$ & $23.7(16.2)$ & $22.6(15.1)$ & $4.4(9.1)$ & $4.4(4.6)$ \\
\hline & 103 & 103 & 103 & 103 & 114 & 114 & 114 & 96 \\
\hline \multirow[t]{2}{*}{$\mathrm{SZ}$} & $65.5(23.2)$ & $18.4(7.7)$ & $15.8(7.7)$ & $31.3(10.2)$ & $27.6(21.0)$ & $31.3(16.0)$ & $2.5(3.3)$ & $4.3(4.5)$ \\
\hline & 35 & 35 & 35 & 35 & 39 & 39 & 39 & 33 \\
\hline \multirow[t]{2}{*}{ SF } & $63.0(-)$ & $17.5(-)$ & $16.5(-)$ & $29.0(-)$ & $19.0(-)$ & $20.3(-)$ & $10.9(-)$ & $3.3(-)$ \\
\hline & 2 & 2 & 2 & 2 & 3 & 3 & 3 & 2 \\
\hline \multirow[t]{2}{*}{$\mathrm{BrP}$} & $71.7(25.6)$ & $22.8(11.2)$ & $14.8(8.1)$ & 34.0 (12.4) & $18.7(18.2)$ & $18.6(12.9)$ & $0.9(1.5)$ & $4.9(5.5)$ \\
\hline & 6 & 6 & 6 & 6 & 7 & 7 & 7 & 7 \\
\hline \multirow[t]{2}{*}{ SA } & $90.0(-)$ & $25.0(-)$ & $24.0(-)$ & $41.1(-)$ & $42.0(-)$ & $25.0(-)$ & $8.0(-)$ & $1.0(-)$ \\
\hline & 2 & 2 & 2 & 2 & 2 & 2 & 2 & 2 \\
\hline \multirow[t]{2}{*}{$\mathrm{BD}$} & $56.0(12.5)$ & $20.2(8.3)$ & $9.3(3.0)^{* *}$ & $26.5(6.5)$ & $28.5(13.4)$ & $13.1(13.7)^{* * *}$ & $18.4(21.1)^{* * *}$ & $4.4(4.8)$ \\
\hline & 12 & 12 & 12 & 12 & 13 & 13 & 13 & 11 \\
\hline \multirow[t]{2}{*}{ MDDP } & $56.8(15.3)$ & $15.9(6.6)$ & $12.8(5.6)$ & $28.1(7.4)$ & 18.5 (11.1) & $21.2(13.6)^{*}$ & $2.3(2.8)$ & $6.2(5.2)$ \\
\hline & 25 & 25 & 25 & 25 & 26 & 26 & 26 & 23 \\
\hline \multirow[t]{2}{*}{$\mathrm{DD}$} & $48.0(-)$ & $16.0(-)$ & $9.0(-)$ & $23.0(-)$ & $13.5(-)$ & $10.0(-)$ & $0.5(-)$ & $0.0(-)$ \\
\hline & 1 & 1 & 1 & 1 & 2 & 2 & 2 & 1 \\
\hline \multirow[t]{2}{*}{ SIP } & $56.5(15.7)$ & $18.2(7.4)$ & $12.1(4.7)$ & $26.2(7.6)$ & $21.2(9.8)$ & $20.1(9.6)^{*}$ & $3.9(4.0)$ & $3.5(3.7)$ \\
\hline & 13 & 13 & 13 & 13 & 15 & 15 & 15 & 10 \\
\hline \multirow[t]{2}{*}{ PGMC } & 49.4 (10.6) & $14.0(4.7)$ & $11.4(4.8)$ & $24.0(6.1)$ & $21.6(14.0)$ & $10.4(11.7)^{* *}$ & $2.0(3.9)$ & $2.0(3.1)$ \\
\hline & 5 & 5 & 5 & 5 & 5 & 5 & 5 & 5 \\
\hline \multirow[t]{2}{*}{ PNOS } & $76.0(-)$ & $29.5(-)$ & $17.0(-)$ & $29.5(12.0)$ & $23.0(-)$ & $15.0(-)$ & $12.7(-)$ & $4.0(-)$ \\
\hline & 2 & 2 & 2 & 2 & 2 & 2 & 2 & 2 \\
\hline
\end{tabular}

PANSS, Positive and Negative Syndrome Scale: PANSS-t, total symptoms; PANSS-p, positive symptom subscale; PANSS-n, negative symptom subscale; PANSS-g, general symptom subscale; SAPS, Scale for the Assessment of Positive Symptoms; SANS, Scale for the Assessment of Negative Symptoms; YMRS, Young Mania Rating Scale; CDSS, Calgary Depression Scale for Schizophrenia; SZ, schizophrenia; SF, schizophreniform disorder; BrP, brief psychotic disorder; SA, schizoaffective disorder; BD, bipolar I disorder; MDDP, major depressive disorder with psychotic features; DD, delusional disorder; SIP, substance-induced psychotic disorder; PGMC, psychotic disorder due to a general medical condition; PNOS, psychotic disorder not otherwise specified. Data are mean scores (S.D.), number of cases.

${ }^{*} p<0.05$.

$* * p<0.02$.

$* * * p<0.001$ v. SZ as reference.

\section{Initiation of antipsychotic treatment}

Among the 115 referrals, 109 (94.8\%) received initial treatment with an antipsychotic on the day of first presentation with psychosis; for five cases antipsychotic treatment was initiated at 1-27 days after first presentation (for three cases of MDDP after 1, 4, and 5 days; for one case of 'disorganised' SZ after 14 days; for one case of SIP after 27 days); for one case of PGMC no antipsychotic was prescribed and the antiepileptic drug valproate was initiated on the day of first presentation for psychosis associated with epilepsy. For the 114 referrals receiving antipsychotic treatment, this was initiated for 111 $(97.4 \%)$ with a second-generation agent (aripiprazole, $n=4$; olanzapine, $n=78$; quetiapine, $n=9$; risperidone, $n=20)$ and for $3(2.6 \%)$ with a first-generation agent [each haloperidol]; other non-antipsychotic drugs were prescribed according to clinical need.

\section{Discussion}

This report documents the origins, development, initiation, and operation of COPE and presents prospective research findings during its first 5 years of operation, that is, for inceptions over 4.5 years in relation to diagnoses at 6 months post-inception.

\section{Operational aspects}

Critically for an EIS (Clarke et al. 2016), median delay from first psychotic presentation, whether via their GP or the Emergency Department, to initiation of antipsychotic treatment was 0 days, with this being longer than 0 for only five of 114 cases $(4.4 \%)$ whose presentations were among the more complex and included the turmoil of affective and drug-induced psychotic symptoms. These rapid referrals to CMMHS and on to COPE, most commonly initiated via GPs and resulting in timely access to care with swift initiation of antipsychotic treatment, attest the value placed in CMMHS on close working relationships with primary care (Russell et al. 2003).

While instances of FEP aged less than 16 were not incepted into COPE, such cases are extremely rare (Driver et al. 2020) and only two cases aged 16 or 17 were referred to COPE via CAMHS. However, an 
Table 4. MMSE, EXIT, BIS, SUMD, QLS, MGAF1, MGAF2, and MGAF3 scores by diagnostic category at 6 months

\begin{tabular}{|c|c|c|c|c|c|c|c|c|}
\hline Diagnosis & MMSE & EXIT & BIS & SUMD & QLS & MGAF1 & MGAF2 & MGAF3 \\
\hline \multirow[t]{2}{*}{ All psychoses } & $27.9(2.4)$ & $12.3(5.9)$ & $5.6(2.3)$ & $9.4(1.9)$ & $86.1(26.7)$ & $57.9(17.3)$ & $64.5(15.0)$ & 48.6 (13.8) \\
\hline & 106 & 103 & 98 & 98 & 113 & 114 & 114 & 114 \\
\hline \multirow[t]{2}{*}{ SZ } & $27.9(2.5)$ & $11.4(6.4)$ & $5.5(2.5)$ & $9.5(2.2)$ & $77.9(27.9)$ & $55.3(18.6)$ & $60.0(16.5)$ & 45.5 (12.6) \\
\hline & 37 & 36 & 35 & 34 & 39 & 39 & 39 & 39 \\
\hline \multirow[t]{2}{*}{ SF } & $30.0(-)$ & $9.0(-)$ & $7.5(-)$ & $8.3(-)$ & $87.3(-)$ & $51.7(7.6)$ & $58.3(18.9)$ & $45.0(5.0)$ \\
\hline & 2 & 2 & 2 & 2 & 3 & 3 & 3 & 3 \\
\hline \multirow[t]{2}{*}{$\mathrm{BrP}$} & $27.9(2.1)$ & $17.2(8.1)$ & $4.1(2.5)$ & $9.4(0.9)$ & $78.0(26.4)$ & $57.9(14.1)$ & $63.6(6.3)$ & 55.7 (18.8) \\
\hline & 7 & 6 & 7 & 6 & 7 & 7 & 7 & 7 \\
\hline \multirow[t]{2}{*}{ SA } & $26.0(-)$ & $14.5(-)$ & $5.0(-)$ & $8.5(-)$ & $79.5(-)$ & $60.0(-)$ & $65.0(-)$ & $32.5(-)$ \\
\hline & 2 & 2 & 2 & 2 & 2 & 2 & 2 & 2 \\
\hline \multirow[t]{2}{*}{$\mathrm{BD}$} & $28.1(2.8)$ & $12.6(5.3)$ & $6.2(2.0)$ & $8.5(1.7)$ & $98.5(15.8)$ & $65.0(15.8)$ & 71.5 (12.6) & 56.5 (15.6) \\
\hline & 12 & 12 & 11 & 11 & 13 & 13 & 13 & 13 \\
\hline \multirow[t]{2}{*}{ MDDP } & $27.4(2.6)$ & $12.3(6.5)$ & $5.8(1.9)$ & $9.4(1.4)$ & $89.3(25.4)$ & $61.0(18.4)$ & $68.7(14.4)$ & 48.5 (14.8) \\
\hline & 25 & 25 & 23 & 23 & 25 & 26 & 26 & 26 \\
\hline \multirow[t]{2}{*}{ DD } & $29.0(-)$ & $8.0(-)$ & $10.0(-)$ & $12.0(-)$ & $79.0(-)$ & $65.0(-)$ & $57.5(-)$ & $40.0(-)$ \\
\hline & 2 & 1 & 1 & 1 & 2 & 2 & 2 & 2 \\
\hline \multirow[t]{2}{*}{ SIP } & $28.9(1.5)$ & $12.4(4.9)$ & $5.5(1.3)$ & $9.6(1.7)$ & $92.3(29.9)$ & $51.0(14.5)$ & $62.3(12.4)$ & 49.3 (10.3) \\
\hline & 12 & 12 & 10 & 12 & 15 & 15 & 15 & 15 \\
\hline \multirow[t]{2}{*}{ PGMC } & $28.2(1.8)$ & $12.0(2.3)$ & $4.2(1.9)$ & $10.1(2.9)$ & $95.0(21.3)$ & $66.0(8.9)$ & $77.0(15.7)$ & 56.0 (12.9) \\
\hline & 5 & 5 & 5 & 5 & 5 & 5 & 5 & 5 \\
\hline \multirow[t]{2}{*}{ PNOS } & $27.0(-)$ & $15.5(-)$ & $6.0(-)$ & $8.8(-)$ & $93.5(-)$ & $52.5(-)$ & $55.0(-)$ & $42.5(-)$ \\
\hline & 2 & 2 & 2 & 2 & 2 & 2 & 2 & 2 \\
\hline
\end{tabular}

MMSE, mini-mental state examination; EXIT, executive interview; BIS, birchwood insight scale; SUMD, scale to assess unawareness of mental disorder; QLS, quality of life scale; MGAF1, MIRECC global assessment of functioning scale-occupational functioning; MGAF2, MIRECC global assessment of functioning scale - social functioning; MGAF3, MIRECC global assessment of functioning scale - symptomatic functioning; SZ, schizophrenia; SF, schizophreniform disorder; BrP, brief psychotic disorder; SA, schizoaffective disorder; BD, bipolar I disorder; MDDP, major depressive disorder with psychotic features; DD, delusional disorder; SIP, substance-induced psychotic disorder; PGMC, psychotic disorder due to a general medical condition; PNOS, psychotic disorder not otherwise specified.

Data are mean scores (S.D.), number of cases.

unexpected aspect of COPE, despite no arbitrary upper age cut-off, was referral of only three cases aged over 65, two via MHSE and one via CMHT. Late onset psychosis is increasingly recognised when arbitrary upper age cut-offs are not applied (Van Assche et al. 2017; Stafford et al. 2018; Nkire et al. 2021b). Furthermore, such instances typically involve an over-representation of MDDP relative to SZ and other FEP diagnoses (Jaaskelainen et al. 2018; Stafford et al. 2018; Nkire et al. 2021b; Waddington et al. 2021). That few older cases of MDDP were incepted into COPE may be influenced by occasional clinical decisions that MHSE was best placed to provide optimal care for some instances of FEP in older persons. Individuals presenting with late-onset FEP constitute an under-appreciated group where EIS has received little investigation and its effectiveness remains to be clarified (Lappin et al. 2016; O'Driscoll et al. 2021).

Though the social demography of persons incepted into the three previously reported EIS in Ireland (Lyne et al. 2015; Lalevic et al. 2019; Murray \& O'Connor, 2019) are generally similar to those described here for COPE, it is difficult to make systematic comparisons due to differences in urban versus rural setting, EIS model adopted, structure of the mental health services within which each EIS is embedded, prospective versus retrospective collection of data, presence versus absence of an integrated research component, and scope of reporting operational aspects vis-à-vis clinical evaluations. Though diverse, at this early stage in the journey to EIS in Ireland (Clarke et al. 2016; Power, 2019) each has value within its own frame-of-reference and adds to the knowledge base that may assist other mental health services as they move to implement EIS.

\section{Research findings}

As expected in the absence of any arbitrary diagnostic restriction or upper age cut-off, the epidemiology of inceptions into COPE was generally similar to that of FEP in CAMFEPS (Nkire et al. 2021b): diagnostic diversity and overall male preponderance that was more marked for SZ and particularly SIP and less evident for non-schizophrenia spectrum diagnoses; yet the most populous functional FEP diagnoses (SZ, BD, and MDDP) were each evident in both sexes from the 
Table 5. DUP and DUI with PAS and NART scores by diagnostic category at 6 months

\begin{tabular}{|c|c|c|c|c|}
\hline Diagnosis & DUP & DUI & NART & PAS \\
\hline \multirow[t]{4}{*}{ All psychoses } & $5.7(14.5)$ & $14.7(24.3)$ & $32.4(9.9)$ & $22.2(9.1)$ \\
\hline & $1.4\{2.3\}$ & $4.0\{16.8\}$ & - & - \\
\hline & {$[0.0-75.4]$} & {$[0.0-124.1]$} & - & - \\
\hline & 112 & 112 & 96 & 101 \\
\hline \multirow[t]{4}{*}{ SZ } & $9.4(20.2)$ & $23.6(32.6)$ & $33.2(10.1)$ & $24.8(10.5)$ \\
\hline & $1.6\{4.6\}$ & $8.2\{27.0\}$ & - & - \\
\hline & {$[0.1-75.4]$} & [0.1-124.1] & - & - \\
\hline & 38 & 38 & 33 & 34 \\
\hline \multirow[t]{4}{*}{ SF } & $1.4(-)$ & $3.3(-)$ & $43.5(-)$ & $17.5(-)$ \\
\hline & $1.5\{-\}$ & $3.0\{-\}$ & - & - \\
\hline & {$[0.2-2.5]$} & [2.4-4.5] & - & - \\
\hline & 3 & 3 & 2 & 2 \\
\hline \multirow[t]{4}{*}{$\mathrm{BrP}$} & $5.6(13.9)$ & $9.4(13.8)$ & $35.8(8.3)$ & $21.7(6.2)$ \\
\hline & $0.2\{0.9\}$ & $0.9\{16.9\}$ & - & - \\
\hline & {$[0.0-37.1]$} & {$[0.0-37.1]$} & - & - \\
\hline & 7 & 7 & 5 & 6 \\
\hline \multirow[t]{4}{*}{ SA } & $1.0(-)$ & $12.7(6.7)$ & $27.0(-)$ & $22.5(-)$ \\
\hline & $1.0\{-\}$ & $12.7\{-\}$ & - & - \\
\hline & [0.2-1.8] & [7.9-17.4] & - & - \\
\hline & 2 & 2 & 2 & 2 \\
\hline \multirow[t]{4}{*}{$\mathrm{BD}$} & $0.7(0.9)^{*}$ & $3.8(6.0)^{* *}$ & $34.0(7.9)$ & $21.3(6.9)$ \\
\hline & $0.2\{1.0\}$ & $1.7\{4.1\}$ & - & - \\
\hline & [0.1-2.6] & [0.1-22.4] & - & - \\
\hline & 13 & 13 & 11 & 12 \\
\hline \multirow[t]{4}{*}{ MDDP } & $5.7(11.8)$ & $14.0(20.2)$ & 30.7 (11.3) & $21.8(9.9)$ \\
\hline & $1.8\{4.0\}$ & $4.7\{23.0\}$ & - & - \\
\hline & [0.0-51.9] & [0.3-88.4] & - & - \\
\hline & 26 & 26 & 24 & 25 \\
\hline \multirow[t]{4}{*}{ DD } & $5.3(-)$ & $16.7(-)$ & $28.0(-)$ & $17.0(-)$ \\
\hline & $5.3\{-\}$ & $16.7\{-\}$ & - & - \\
\hline & [0.1-10.5] & [0.7-32.7] & - & - \\
\hline & 2 & 2 & 1 & 1 \\
\hline \multirow[t]{4}{*}{ SIP } & $4.6(13.7)$ & $11.1(24.7)$ & 31.8 (10.7) & $19.3(8.8)$ \\
\hline & $0.5\{1.5\}$ & $1.6\{7.8\}$ & - & - \\
\hline & [0.0-51.9] & [0.1-88.4] & - & - \\
\hline & 14 & 14 & 12 & 12 \\
\hline \multirow[t]{4}{*}{ PGMC } & $1.1(1.3)$ & $5.8(6.3)$ & $29.8(10.2)$ & $19.6(4.6)$ \\
\hline & $0.1\{2.4\}$ & $3.6\{12.1\}$ & - & - \\
\hline & [0.1-2.9] & [0.2-14.4] & - & - \\
\hline & 5 & 5 & 4 & 5 \\
\hline \multirow[t]{4}{*}{ PNOS } & $0.8(-)$ & $9.6(-)$ & $29.0(-)$ & $22.5(-)$ \\
\hline & $0.8\{-\}$ & $9.6\{-\}$ & - & - \\
\hline & [0.1-1.5] & [1.8-17.4] & - & - \\
\hline & 2 & 2 & 2 & 2 \\
\hline \multicolumn{5}{|c|}{$\begin{array}{l}\text { SZ, schizophrenia; SF, schizophreniform disorder; BrP, brief psychotic disorder; } \\
\text { disorder; MDDP, major depressive disorder with psychotic features; DD, de } \\
\text { psychotic disorder; PGMC, psychotic disorder due to a general medical } \\
\text { otherwise specified. } \\
\text { Data for DUP and DUI are mean (s.D.), median [interquartile range\}, [range] in r } \\
\text { Data for NART and PAS scores are means (s.D.) and number of cases. } \\
{ }^{*} p=0.05 \text {. } \\
{ }^{* *} p=0.02 v \text {. schizophrenia as reference, analysed using logDUP and logDUI. }\end{array}$} \\
\hline
\end{tabular}

late teens through to the tenth decade. The one epidemiological finding evident in CAMFEPS but not in COPE was older age at FEP among females and
MDDP. This may reflect the relatively few cases of late-onset psychosis referred to COPE, which typically contain an enrichment of females and MDDP (van der 
Werf et al. 2014; Stafford et al. 2018; Waddington et al. 2021).

Positive and general PANSS symptoms for inceptions into COPE did not differ between diagnoses; PANSS negative symptoms were lower in BD than in SZ, as noted in CAMFEPS (Nkire et al. 2021b). COPE utilised also the SAPS, SANS, YMRS, and CDSS that confirmed an indistinguishable level of positive symptoms across the diagnoses and extended the lower level of negative symptoms in BD also to MDDP, SIP, and PGMC. Furthermore, BD was the only diagnosis showing a higher level of manic symptoms, suggesting phenomenological incompatibility between negative symptoms and elation/grandiosity during an acute manic episode. While MDDP also evidenced a lower level of negative symptoms using the SANS, the level of depressive symptoms using the CDSS was similar across diagnoses, suggesting that assessment of negative symptoms in MDDP was not materially confounded with depressive symptoms. Both SIP and PGMC also evidenced not only levels of positive symptoms indistinguishable from SZ, BD, and MDDP but also a lower level of negative symptoms as evident in BD and MDDP. This suggests that underlying causal factors for positive symptoms in SIP and PGMC may involve mechanisms that overlap with those underlying positive symptoms across the functional psychoses, while mechanisms underlying negative symptoms operate to a greater extent in SZ.

For BrP, levels of initial psychopathology at FEP were similar to those for other functional psychotic diagnoses and for SIP and PGMC but declined rapidly thereafter. In CAMFEPS, while BrP at FEP was characterised similarly by rapid remission, at 6-year follow-up the majority now received a functional psychotic diagnosis of SZ, SA, DD, BD or MDDP (Kingston et al. 2013). We note in COPE that among nine cases of $\mathrm{BrP}$ at FEP, at 6 months two received a functional psychotic diagnosis: one SZ and one BD. While longterm follow-up of the COPE cohort will further clarify these issues, findings to date reinforce concern that $\mathrm{BrP}$ may not be a benign occurrence. For some, it appears to be an early, transient harbinger of long-term evolution to functional psychotic illness that may benefit from continuing review.

Neuropsychology, insight, quality of life, and functionality at FEP did not differ between the functional psychotic diagnoses, SIP and PGMC; these findings are similar to those for MMSE, EXIT, SUMD, and QLS in CAMFEPS. MMSE scores indicated the absence of general cognitive impairment and EXIT scores indicated a modest level of impairment in executive/ frontal lobe dysfunction. MGAF1, 2, and 3 scores were each in the borderline-dysfunctional range. In terms of premorbid indices, neither NART nor PAS scores differed between the functional psychotic diagnoses, SIP and PGMC; these findings are also similar to those for CAMFEPS. Both SAS and AIMS scores were so low as to preclude analysis. This would be consistent with assessments made early in the course of minimal exposure to antipsychotic drugs, the overwhelming majority of which were second-generation agents.

Assessment of DUP was extended to the underinvestigated and potentially more insidious variable of DUI (Norman \& Malla, 2001; Clarke et al. 2016; Nkire et al. 2021a); for DUI, the added interval preceding DUP includes often more prolonged periods of functional deficits, psychological anomalies and subthreshold psychotic ideation that overlap with what is variously referred to as the psychosis prodrome, the clinical high-risk state for psychosis and attenuated psychosis syndrome (Waddington et al. 2012; Clarke et al. 2016; Nkire et al. 2021a). Both DUP and DUI were characterised by marked right-shift distributions with medians considerably shorter that means, due to the majority of shorter values but a minority of longer and sometimes very long values, as noted previously (Norman \& Malla, 2001; Penttila et al. 2014; RegisterBrown \& Hong, 2014; Clarke et al. 2016; Nkire et al. 2021a).

Values for DUP and DUI were longest for SZ, intermediate for MDDP and SIP, and shortest for BD, reflecting the typically more acute onset of a first manic episode. These DUP values for undifferentiated FEP and for SZ are within but towards the lower end of the range typically reported in FEP populations (Norman \& Malla, 2001; Penttila et al. 2014; Register-Brown \& Hong, 2014; Clarke et al. 2016) and are not dissimilar to values reported by DETECT (Lyne et al. 2015) and by the North Lee Mental Health Service EIS (Lalevic et al. 2019) and South Lee Mental Health Service EIS (Murray \& O'Connor, 2019).

DUP and DUI in PGMC have received little previous investigation; despite the rarity and heterogeneity of PGMC, values were generally comparable with functional psychotic illness, suggesting the emergence of psychosis on a background of psychological features that may evolve in contiguity with the underlying medical condition.

These assessments inform systematically on the comparative durations of DUP and DUI for individual functional psychotic diagnoses, SIP and PGMC. They are important for evaluating in future studies: (a) any impact of COPE on DUP and DUI, requiring as reference a matched CAMFEPS dataset; (b) associations in COPE between DUP/DUI and clinical state at FEP; and (c) those same associations at long-term follow-up of the COPE cohort. 


\section{Limitations}

Individuals experiencing FEP under age 16 were not included and inceptions of late-onset FEP were fewer than expected, limiting the generalizability of findings. For a very small percentage of FEP experiencing complex presentations $(<5 \%)$, otherwise rapid initiation of antipsychotic treatment was delayed for some days. The clinical imperative to initiate antipsychotic treatment at the earliest possible stage meant that some influence of that treatment on assessments, however small, could not be excluded.

\section{Conclusions}

These vicissitudes in the development, operation, and suspension of COPE may be helpful to other mental health services in Ireland as they develop and initiate their own EIS. Findings to date are heuristic in systematically resolving, across the full diagnostic diversity of EIS, that variations in epidemiology and clinical features are quantitative rather than qualitative, with few points of rarity between psychotic diagnoses. Importantly, by using more incisive instruments these findings elaborate and extend those apparent in CAMFEPS (Nkire et al. 2021b). More specifically, each of SZ, BD, MDDP, SIP, and PGMC show indistinguishable levels of positive psychotic symptoms and multiple other domains of premorbid functioning and of current impairment and dysfunction, with only negative symptoms in SZ and mania in BD showing quantitative variations.

These findings further elaborate clinical, genetic, and neuroimaging findings that SZ, BD, and MDDP have arbitrary and porous diagnostic boundaries that reflect two realities: first, genetic and environmental factors that interact in a common, transdiagnostic milieu (Brainstorm Consortium, 2018; Castillejos et al. 2018; Guloksuz \& van Os, 2018; Jongsma et al. 2018; Waddington \& Russell, 2019); second, dysfunction in one or more components of a common neuronal network that has been implicated in the transdiagnostic pathobiology of SZ, BD, and MDDP (Goodkind et al. 2015; Sheffield et al. 2017; Baker et al. 2018; Ma et al. 2019; Tu et al. 2019; Huang et al. 2020) and extends to both PGMC (Joyce, 2018; Waddington, 2020) and SIP (Khokhar et al. 2018).

\section{Acknowledgements}

We thank the staff of Cavan-Monaghan Mental Health Service and Drs Savio Sardinha and Pranith Perera for all their contributions to COPE, Professor Ronan Conroy, RCSI Data Science Centre, for assisting in analysis of incidence data and Professor Mary Clarke and her colleagues at DETECT for their kind assistance.

\section{Conflict of interest}

The authors declare no conflict of interest.

\section{Ethical standards}

All protocols relating to COPE were approved by the Research Ethics Committee of the Health Service Executive Dublin North East Area. The authors assert that all procedures contributing to this work comply with the ethical standards of the relevant national and institutional committee on human experimentation and with the Helsinki Declaration of 1975, as revised in 2008.

\section{Financial support}

COPE was not supported by any external funding and was integral to Cavan-Monaghan Mental Health Service.

\section{References}

Addington J, Addington D, Schissel BA (1990). A depression rating scale for schizophrenics. Schizophrenia Research 3, 247-251.

Amador XF, Strauss DH, Yale SA, Flaum MM, Endicott J, Gorman JM (1993). Assessment of insight in psychosis. American Journal of Psychiatry 150, 873-879.

Andreasen NC (1983). The Scale for the Assessment of Negative Symptoms (SANS). The University of Iowa: Iowa City.

Andreasen NC (1984). The Scale for the Assessment of Positive Symptoms (SAPS). The University of Iowa: Iowa City.

Baker JT, Dillon DG, Patrick LM, Roffman JL, Brady RO, Pizzagalli DA, Ongur D, Holmes AJ (2018). Functional connectomics of affective and psychotic pathology. Proceedings of the National Academy of Sciences USA 116, 9050-9059.

Baldwin P, Browne D, Scully PJ, Quinn JF, Morgan MJ, Kinsella A, Owens JM, Russell V, Waddington JL (2005). Epidemiology of first-episode psychosis: illustrating the challenges across diagnostic boundaries through the Cavan/Monaghan study at 8 years. Schizophrenia Bulletin 31, 624-638.

Behan C, Kennelly B, Roche E, Renwick L, Masterson S, Lyne J, O'Donoghue B, Waddington J, McDonough C, McCrone P, Clarke M (2020). Early intervention in psychosis: health economic evaluation using the net benefit approach in a real-world setting. British Journal of Psychiatry 217, 484-490.

Beiser M, Erickson D, Fleming JAE, Iacono WG (1993). Establishing the onset of psychotic illness. American Journal of Psychiatry 150, 1349-1354.

Birchwood M, Smith J, Drury V, Healy J, Macmillan F, Slade M (1994). A self-report insight scale for psychosis: reliability, validity and sensitivity to change. Acta Psychiatrica Scandinavica 89, 62-67 
Brainstorm Consortium (2018). Analysis of shared heritability in common disorders of the brain. Science 360, eaap8757.

Cannon-Spoor HE, Potkin SG, Wyatt RJ (1982). Measurement of premorbid adjustment in chronic schizophrenia. Schizophrenia Bulletin 8, 470-484.

Castillejos MC, Martin-Perez C, Moreno-Kustner B (2018). A systematic review and meta-analysis of the incidence of psychotic disorders: the distribution of rates and the influence of gender, urbanicity, immigration and socio-economic level. Psychological Medicine, 1-15. doi: 10.1017/S0033291718000235.

Chan SWA, Chan SWY, Pang HH, Yan KK, Hui CLM, Chang WC, Lee EHM, Chen EYH (2018). Association of an early intervention service for psychosis with suicide rate among patients with first-episode schizophreniaspectrum disorders. JAMA Psychiatry 75, 458-464.

Clarke M, McDonough CM, Doyle R, Waddington JL (2016). Are we really impacting duration of untreated psychosis and does it matter? Longitudinal perspectives from the Irish Public Health Services. Psychiatric Clinics of North America 39, 175-186.

Correll CU, Galling B, Pawar A, Krivko A, Bonetto C, Ruggeri $\mathbf{M}$ et al. (2018). Comparison of early intervention services versus treatment as usual for early phase psychosis: a systematic review, meta-analysis and meta-regression. JAMA Psychiatry 75, 555-565.

Driver DI, Thomas S, Gogtay N, Rapoport JL (2020). Childhood-onset schizophrenia and early-onset schizophrenia spectrum disorders: an update. Child and Adolescent Psychiatric Clinics of North America 29, 71-90.

First MB, Spitzer RL, Gibbon M, Williams JB (2002). Structured Clinical Interview for the DSM-IV Axis I Disorders. Biometrics Research: New York.

Folstein MF, Folstein SE, McHugh PR (1975). "Mini-mental state". A practical method for grading the cognitive state of patients for the clinician. Journal of Psychiatric Research 12, 189-198.

Fusar-Poli P (2017). The clinical high risk state for psychosis (CHR-P), version II. Schizophrenia Bulletin 43, $44-47$.

Goodkind M, Eickhoff SB, Oathes DJ, Jiang Y, Chang A, Jones-Hagata LB, Ortega BN, Zaiko YV, Roach EL, Korgaonkar MS, Grieve SM, Galatzer-Levy I, Fox PT, Etkin A (2015). Identification of a common neurobiological substrate for mental illness. JAMA Psychiatry 72, 305-315.

Guloksuz S, van Os J (2018). The slow death of the concept of schizophrenia and the painful birth of the psychosis spectrum. Psychological Medicine 48, 229-244.

Guy W (1976). ECDEU Assessment Manual for Psychopharmacology: Publication ADM 76-338. US Department of Health, Education, and Welfare: Washington, DC.

Heinrichs DW, Hanlon TE, Carpenter WT (1984). The quality of life scale: an instrument for rating the schizophrenic deficit syndrome. Schizophrenia Bulletin 10, 388-398.
Huang CC, Luo Q, Palaniyappan L, Yang AC, Hung CC, Chou KH, Lo CYZ, Liu MN, Tsai SJ, Barch DM, Feng J, Lin CP, Robbins TW (2020). Transdiagnostic and illness-specific functional dysconnectivity across schizophrenia, bipolar disorder, and major depressive disorder. Biological Psychiatry Cognitive Neuroscience and Neuroimaging 5, 542-553.

Jääskeläinen E, Juola T, Korpela H, Lehtiniemi H, Nietola M, Korkeila J, Miettunen J (2018). Epidemiology of psychotic depression - systematic review and metaanalysis. Psychological Medicine 48, 905-918.

Jongsma HE, Gayer-Anderson C, Lasalvia A, Quattrone D, Mulè A, Szöke A et al. (2018). Treated incidence of psychotic disorders in the multinational EU-GEI study. JAMA Psychiatry 75, 36-46.

Joyce EM (2018). Organic psychosis: the pathobiology and treatment of delusions. CNS Neuroscience and Therapeutics 24, 598-603.

Kay SR, Fiszbein A, Opler LA (1987). The positive and negative syndrome scale (PANSS) for schizophrenia. Schizophrenia Bulletin 13, 261-276.

Khokhar JY, Dwiel LL, Henricks AM, Doucette WT, Green AI (2018). The link between schizophrenia and substance use disorder: a unifying hypothesis. Schizophrenia Research 194, 78-85.

Kingston T, Scully PJ, Browne DJ, Baldwin PA, Kinsella A, Russell V, O'Callaghan E, Waddington JL (2013). Diagnostic trajectory, interplay and convergence/ divergence across all 12 DSM-IV psychotic diagnoses: 6-year follow-up of the Cavan-Monaghan First Episode Psychosis Study (CAMFEPS). Psychological Medicine 43, 2523-2533.

Lalevic G, Scriven M, O'Brien S (2019). Early intervention in psychosis in the North Lee Mental Health Services programme: a 5-year review. Irish Journal of Psychological Medicine 36, 271-277.

Lappin JM, Heslin M, Jones PB, Doody GA, Reininghaus UA, Demjaha A, Croudace T, Jamieson-Craig T, Donoghue K, Lomas B, Fearon P, Murray RM, Dazzan P, Morgan C (2016). Outcomes following first-episode psychosis - Why we should intervene early in all ages, not only in youth. Australian and New Zealand Journal of Psychiatry 50, 1055-1063.

Lyne J, O'Donoghue B, Roche E, Behan C, Jordan I, Renwick L, Turner N, O'Callaghan E, Clarke M (2015). Illness characteristics and symptoms in an Irish early intervention for psychosis service. Irish Journal of Psychological Medicine 32, 147-154.

Ma Q, Tang Y, Wang F, Liao X, Jiang X, Wei S, Mechelli A, He Y, Xia M (2019). Transdiagnostic dysfunctions in brain modules across patients with schizophrenia, bipolar disorder, and major depressive disorder: a connectome-based study. Schizophrenia Bulletin 46, 699-712.

McCauley M, Rooney S, Clarke C, Carey T, Owens J (2003). Home-based treatment in Monaghan: the first 2 years. Irish Journal of Psychological Medicine 20, 11-14. 
Murray N, O'Connor K (2019). Retrospective study of a first-episode psychosis service embedded within a home-based treatment team. Irish Journal of Psychological Medicine 36, 265-269.

Nelson HE (1982). National Reading Test (NART): Test Manual. NFER-Nelson: Windsor.

Niv N, Cohen AN, Sullivan G, Young AS (2007). The MIRECC version of the global assessment of functioning scale: reliability and validity. Psychiatric Services 58, 529-535.

Nkire N, Sardinha S, Nwosu N, McDonough C, De Coteau PA, Duffy I, Waddington JL, Russell V (2015). Evaluation of knowledge and attitudes among primary care physicians in Cavan-Monaghan as 'gatekeepers-in-waiting' for the introduction of Carepath for Overcoming Psychosis Early. Early Intervention in Psychiatry 9, 141-150.

Nkire N, Scully PJ, Browne DJ, Baldwin PA, Kingston T, Owoeye O, Kinsella A, O'Callaghan E, Russell V, Waddington JL (2021a). Systematic comparison of duration of untreated illness versus duration of untreated psychosis in relation to psychopathology and dysfunction in the Cavan-Monaghan first episode psychosis study (CAMFEPS). European Neuropsychopharmacology 47, 20-30.

Nkire N, Scully PJ, Browne DJ, Baldwin PA, Kingston T, Owoeye O, Kinsella A, O'Callaghan E, Russell V, Waddington JL (2021b). Systematic epidemiological and clinical comparisons across all 12 DSM-IV psychotic diagnoses in the Cavan-Monaghan First Episode Psychosis Study (CAMFEPS). Psychological Medicine 51, 607-616

Norman RMG, Malla AK (2001). Duration of untreated psychosis: a critical examination of the concept and its importance. Psychological Medicine 31, 391-400.

Nwachukwu I, Nkire N, Russell V (2014). Profile and activities of a rural home-based treatment service in Ireland. International Journal of Psychiatry in Clinical Practice 18, 125-130.

O'Driscoll C, Free K, Attard A, Carter P, Mason J, Shaikh M (2021). Transitioning to age inclusive early intervention for psychosis. Early Intervention in Psychiatry 15, 34-40.

Omer S, Behan C, Waddington JL, O'Callaghan E (2010). Early intervention in psychosis: service models worldwide and the Irish experience. Irish Journal of Psychological Medicine 27, 210-214.

Penttila M, Jaaskelainen E, Hirvonen N, Isohanni M, Miettunen J (2014). Duration of untreated psychosis as a predictor of long-term outcome in schizophrenia: systematic review and meta-analysis. British Journal of Psychiatry 205, 88-94.

Pollard JM, Ferrara M, Lin I-H, Kucukgoncu S, Wasser T, Li F, Srihari VH (2020). Analysis of early intervention services on adult judicial outcomes. JAMA Psychiatry 77, 871-872.

Power P (2019). Early intervention services for psychosis in Ireland: are we there yet? Irish Journal of Psychological Medicine 36, 243-248.
Register-Brown K, Hong LE (2014). Reliability and validity of methods for measuring the duration of untreated psychosis: a quantitative review and meta-analysis. Schizophrenia Research 160, 20-26.

Royall DR, Mahurin RK, Gray KF (1992). Bedside assessment of executive cognitive impairment: the executive interview. Journal of the American Geriatric Society 40, 1221-1226.

Russell V, McCauley M, MacMahon J, Casey S, McCullagh H, Begley J (2003). Liaison psychiatry in rural general practice. Irish Journal of Psychological Medicine 20, 65-68.

Russell V, Nkire N, Kingston T, Waddington JL (2019). Forging successful partnerships in psychosis research: lessons from the Cavan-Monaghan First Episode Psychosis Study (CAMFEPS). Irish Journal of Psychological Medicine 36, 317-322.

Salazar de Pablo G, Catalan A, Fusar-Poli P (2020). Clinical validity of DSM-5 attenuated psychosis syndrome. Advances in diagnosis, prognosis and treatment. JAMA Psychiatry 77, 311-320.

Sheffield JM, Kandala S, Tamminga CA, Pearlson GD, Keshavan MS, Sweeney JA, Clementz BA, Lerman-Sinkoff DB, Hill SK, Barch DM (2017). Transdiagnostic associations between functional brain network integrity and cognition. JAMA Psychiatry 74, 605-613.

Simpson GM, Angus JW (1970). A rating scale for extrapyramidal side effects. Acta Psychiatrica Scandinavica Supplementum 212, 11-19.

Stafford J, Howard R, Kirkbride JB (2018). The incidence of very late-onset psychotic disorders: a systematic review and meta-analysis, 1960-2016. Psychological Medicine 48, 1775-1786.

Tu PC, Bai YM, Li CT, Chen MH, Lin WC, Chang WC, Su TP (2019). Identification of common thalamocortical dysconnectivity in four major psychiatric disorders. Schizophrenia Bulletin 45, 1143-1151.

Van Assche L, Morrens M, Luyten P, Van de Ven L, Vandenbulcke $\mathbf{M}$ (2017). The neuropsychology and neurobiology of late-onset schizophrenia and very-late-onset schizophrenia-like psychosis: a critical review. Neuroscience and Biobehavioral Reviews 83, 604-621.

Van der Werf M, Hanssen M, Kohler S, Verkaaik M, Verhey FR, RISE Investigators, van Winkel R, van Os J, Allardyce J (2014). Systematic review and collaborative recalculation of 133693 incident cases of schizophrenia. Psychological Medicine 44, 9-16.

Waddington JL (2020). Psychosis in Parkinson's disease and parkinsonism in antipsychotic-naive schizophrenia spectrum psychosis: clinical, nosological and pathobiological challenges. Acta Pharmacologica Sinica 41, 464-470.

Waddington JL, Hennessy RJ, O'Tuathaigh CMP, Owoeye O, Russell V (2012). Schizophrenia and the lifetime trajectory of psychotic illness: developmental neuroscience and pathobiology, redux. In The Origins of 
Schizophrenia (ed. A. S. Brown, P. H. Patterson), pp 3-21. Columbia University Press: New York.

Waddington JL, Kingston T, Nkire N, Russell V (2021).

Major depressive disorder with psychotic features: confronting and resolving the dimensional challenge. In Dimensions of Psychosis: Comprehensive Conceptualization and Treatments (ed. C. A. Tamminga, E. I. Ivleva,

U. Reininghaus, J. van Os), pp. 50-58. Oxford University Press: New York.
Waddington JL, Russell V (2019). The Cavan-Monaghan First Episode Psychosis Study (CAMFEPS): arbitrary diagnostic boundaries across the gene-environment interface and within evolving models of care. Irish Journal of Psychological Medicine 36, 293-303.

Young RC, Biggs JT, Ziegler VE, Meyer DA (1978).

A rating scale for mania: reliability, validity and sensitivity. British Journal of Psychiatry 133, 429-435. 